\title{
DETERMINACIÓN DEL ESPACIO GEOGRÁFICO A PARTIR DE LOS PROCESOS SOCIALES: LA SIERRA DE ENGUERA, 1580-1930 ${ }^{1}$
}

\author{
Josep Rafael Pérez Borredà \\ Doctor en Geografía
}

\begin{abstract}
RESUMEN
El espacio objeto de la geografía es un espacio social, un producto de la acción humana. Las pautas de organización del espacio se fundamentan en la valoración cultural de la naturaleza y en la relación resultante del balance entre las condiciones del medio y las necesidades de la sociedad. La ocupación del suelo está condicionada por factores como el modelo económico, el desarrollo tecnológico y los aspectos culturales que resultan claves en la conformación de la estructura del paisaje. Puede resultar útil para el conocimiento de la formación local, pero también general, del paisaje valenciano, analizar el impacto de los usos del suelo, la distribución de los cultivos y los recursos forestales y pecuarios en el paisaje, lo cual dará como resultado la determinación del espacio geográfico a través de los procesos sociales desarrollados a lo largo de un determinado período en un área cohesionada por la actividad humana.
\end{abstract}

Palabras clave: Sierra de Enguera, paisaje mediterráneo, industria textil, roturaciones, ganadería, agricultura, liberalismo, propiedad, montes de utilidad pública.

\begin{abstract}
The space studied by geography is a social space, a product of human action. The criteria for the organisation of space are based on a cultural appraisal of nature and the relationship resulting from the balance achieved between environmental realities and the needs of society. Occupation of land is conditioned by such factors as economic models, technological development and cultural aspects, which are key elements in shaping the landscape. To understand how the Valencian landscape was created, both locally and as a whole, it could be useful to analyse the impact of land use, crop distribution and forestry and livestock resources on the landscape in order to define the geographic space shaped by the social processes that have taken place over a given period in an area bound together by human activity.
\end{abstract}

1 El presente texto surge tras la reflexión sobre algunos aspectos del texto de mi Tesis Doctoral, titulada Transformar la naturaleza. El modelo de crecimiento agrario del siglo XIX y sus límites ambientales en el secano central valenciano (1580-1930), defendida, en enero de 2009, en la Universitat de València. 
Key words: Sierra de Enguera, Mediterranean landscape, textile industry, ploughing, stockbreeding, agriculture, liberalism, property, woodlands of public benefit.

\section{EL ESPACIO OBJETO DE LA GEOGRAFÍA}

Actualmente, existe un amplio consenso en considerar que el espacio geográfico, o si se quiere, el espacio objeto de la geografía, es un espacio social. Es un producto de la acción humana, de aquí que no sea un objeto dado ni preexistente a la misma, sino que se produce socialmente y, como tal, también históricamente. Este consenso implica un cambio muy importante respecto de las posturas tradicionales en geografía, pues hoy se acepta que el espacio es un objeto a ser indagado en el marco de los procesos sociales que lo involucran, como parte de los mismos, y que esto debe realizarse con las mismas herramientas metodológicas.

El espacio como producto social es un objeto complejo y polifacético: es lo que materialmente la sociedad crea y recrea, con una entidad física definida; es una representación social y es un proyecto, en el que operan individuos, grupos sociales, instituciones, relaciones sociales, con sus propias representaciones y proyectos. El espacio se nos ofrece, además, a través de un discurso socialmente construido, que mediatiza al tiempo que vehicula nuestra representación y nuestras prácticas sociales. Es un producto social porque sólo existe a través de la existencia y reproducción de la sociedad. Este espacio tiene una doble dimensión: es a la vez material y representación mental, objeto físico y objeto mental. Es lo que se denomina espacio geográfico (Ortega Valcárcel, 2004: 33-34).

Es un producto social, reflejo de los valores y contradicciones propias de la sociedad. Responde a una lógica interna. De esto podemos deducir que si todo espacio está organizado podemos buscar leyes que expliquen esa organización. La tarea del geógrafo sería buscar ése orden y explicarlo, racionalizarlo².

El espacio geográfico, resultante de múltiples y complejas interacciones entre elementos de diferente origen, con ritmos distintos de evolución, en procesos de tiempos cortos y largos, rápidos y lentos, inscrito en coordenadas espacio-temporales que afectan a pequeñas o grandes áreas, en construcción constante, es también un espacio de significación que se convierte en referente simbólico con el cual un grupo social se identifica. ${ }^{3}$

2 Un excelente ejercicio de análisis de las transformaciones territoriales valencianas en el siglo XVIII, según un nuevo proyecto social, el del reformismo ilustrado, es la tesis doctoral de Pablo Giménez Font, publicada, en 2008, con el título Las transformaciones del paisaje valenciano en el siglo XVIII: una perspectiva geográfica (Institució Alfons el Magnànim). Para este autor: «El importante desarrollo de las nuevas ideas sobre el hombre y la naturaleza, que comienzan a abrirse paso en el siglo XVIII, tienen su traducción directa en el programa político del reformismo borbónico. Sin parangón en la historia anterior, durante este período los gobernantes asumen la necesidad de acometer acciones territoriales como parte de las funciones del Estado (Capel, 1994 y 2003) y tanto la reorganización administrativa como la reforma fiscal y, en general, la política general de fomento económico, tiene una plasmación directa sobre el espacio, como se verá para el caso valenciano. El proyecto económico repercute también por una mayor preocupación por el inventario de los recursos, lo cual favorece un incremento de la actividad científica y un desarrollo de los colectivos técnicos que mejorará el conocimiento - y la consiguiente reflexión - del territorio. Los resultados de este conjunto de acciones señalará, también la presencia de limitaciones en la explotación del medio ecológico» (2008:23).

3 Jesús Millán (2008) explica el proceso de formación de la huella identitaria en un área geográfica concreta, al hilo de los cambios operados en el espacio durante el triunfo de la agricultura en el extremo sur del País Valencià. Toma como caso paradigmático el municipio de Oriola, allí examina la probable cronología y los factores que ocasionaron el desplazamiento de la lengua catalana por parte del castellano, así como su reflejo en la toponimia de la zona y en la representación colectiva de la ciudad. 
De allí la importancia que reviste poner el énfasis en el abordaje de las interacciones y los procesos como componentes relevantes en el estudio del espacio geográfico. Al respecto es oportuno citar las reflexiones de José Ortega Valcárcel cuando se refiere al «...interés en el cambio, en las transformaciones, (...) como eje de explicación del espacio geográfico, como claves para entender el espacio social»; en este sentido sostiene: «Es un interés que tiene un fundamento teórico. El acento sobre los procesos deriva de la propia naturaleza histórica, construida, atribuida al espacio, a sus elementos. Ni aquél ni éstos vienen dados de forma natural, sino que son el producto de determinados procesos en un momento dado y en un ámbito históricamente determinado. De donde la necesidad de analizar esos procesos de construcción (...). Una construcción que es teórica, que es simbólica, que es material.» (Ortega Valcárcel, 2000: 515).

En un nuevo contexto en el que en la sociedad y en el ámbito académico se va abriendo una nueva cultura del territorio y del paisaje, desde cuyo cambio de valores y el mejor conocimiento de territorios y paisajes se abre camino también una «interesante» experiencia de buenas prácticas en el campo de las políticas de ordenación y gestión de los paisajes en Europa, «es imprescindible disponer de estudios de casos que permitan diseñar políticas de ordenación y gestión» (Romero González, 2009:13)». ${ }^{4}$

Cobra sentido entonces plantear la reconstrucción de las transformaciones de un paisaje mediterráneo causadas por la sociedad que lo habita, lo usa y moldea sus formas hasta otorgarle la categoría de paisaje cultural. Investigar el modelo de gestión del territorio desarrollado por los distintos agentes en la fase temporal que condujo a la implantación del régimen liberal, tal vez el momento histórico precedente en el que se desarrolló una fase de transformación social del territorio sin parangón, hasta el momento, en la historia agraria valenciana, por la magnitud que alcanzó el proceso. ${ }^{5}$ En definitiva, analizar el proceso de determinación del espacio geográfico a partir de los procesos sociales en un período histórico concreto, como puede ser el vivido por la Sierra de Enguera entre 1580 y 1930, que se aceleraron desde mediados del siglo XVIII en adelante.

Debido a las limitaciones de dominio existentes, producto del régimen señorial valenciano, base sobre la que se construyen las transformaciones agrarias del país, un largo pleito, promovido por el municipio en 1846, que no aceptó el dominio absoluto del conde sobre los montes de Enguera conseguido dos años antes en instancias judiciales proclives, acabará en 1867 de manera insatisfactoria para las partes. Pues, la Sentencia de la Sala Tercera de la Audiencia Territorial de Valencia, sancionaba el dominio de los montes (18.000 Ha) a favor del conde de Cervellón, exceptuando la Redonda (6.000 Ha), que incluye el espacio eminentemente agrario y la villa de Enguera. Pero respetaba el derecho de los vecinos a realizar ciertos aprovechamientos, como lo habían efectuado con anterioridad, sin necesidad de solicitar permiso al conde y de forma gratuita. Esta particular situación de condominio posibilitó, en paralelo, que un importante número de vecinos tuviera en 1869 la «posesión de una grandísima parte de la misma convertida en terreno labrantío», según el resultado de un informe sobre el estado de la sierra solicitado por el antiguo señor (Pérez Borredà, 2009).

4 Esta recomendación ha sido magníficamente atendida por Sabina Asins Velis, en su Tesis Doctoral, publicada en libro con el título de (2009) El paisaje agrario aterrazado. Diálogo entre el hombre y el medio en Petrer (Alicante), Universitat de València. La autora, tras analizar la trayectoria de ocupación y uso del territorio en este municipio a lo largo de 6.500 años, que ha conformado un paisaje muy dinámico, realiza una propuesta de futuro, fundamentada en las recomendaciones internacionales, para mantener vivos estos paisajes aterrazados mediante su protección como Bien de Interés Cultural para este legado cultural.

5 Las transformaciones agrarias en el ámbito valenciano durante la segunda mitad del siglo XIX fueron puestas de relieve por Ramon Garrabou (1985). 


\section{GEOGRAFÍA DE LOS PROCESOS SOCIALES}

La explicación de procesos donde suceden muchas cosas simultáneamente es uno de los principales problemas de la geografía. Si el tiempo acostumbra a desarrollar casi siempre un papel en segundo plano aunque imprescindible en geografía (Mendizábal, 1993), en el espacio geográfico, soporte o continente de las múltiples interacciones entre los diversos elementos naturales y humanos, estas interacciones intervienen en el espacio modificándolo o aportando características propias y, a su vez, el espacio condiciona esas mismas interacciones. Finalmente los espacios humanizados serán aquellos territorios donde la actividad humana, pasada o actual, explica los rasgos del espacio. Una vía apropiada para comprender la determinación del espacio geográfico será desentrañar los procesos sociales que en éste tienen lugar. Sin duda, introduciendo la perspectiva histórica en el análisis geográfico del territorio o el recurso a la historia desde la geografía (Mateu, 2001:544), pues, siguiendo un planteamiento coevolutivo entre el medio y la sociedad, el ser humano, respondiendo a las condiciones de la naturaleza, tiene la capacidad de construir su futuro de distintas maneras que no son fáciles de predecir pero que, en todo caso, están determinadas por acciones y elecciones anteriores que quedan plasmadas en el territorio. De esta manera, el pasado se convierte en la clave del presente (Fontana, 2000).

En el caso de Enguera, a partir de una baja densidad demográfica y de la ausencia de la formación de un sistema comunal de aprovechamientos colectivos institucionalizado, cristalizó un modelo de ocupación del territorio, a través de su integración en viviendas o heredamientos diseminados, fundamentada en la libre disposición de raíz individualista. El dominio útil que disfrutaron los vecinos facilitó, inicialmente, la conversión de terrenos forestales comunes en particulares, en una fase de expansión industrial hasta mediados del siglo XIX. Desde 1870, en que el Ayuntamiento fue propietario del área inculta, en representación del común de vecinos, mediante una concordia con el conde de Cervellón, el gobierno local no reguló el proceso individual de apropiación del territorio, en un escenario marcado por una actividad industrial en declive. Finalmente, la declaración del monte como de Utilidad Pública, iniciado a principios del siglo XX, trató de poner freno a una dialéctica social que sobrepasaba el ordenamiento forestal, implementado desde mediados del siglo XIX, y que se traducía en un esquema de utilización de los recursos naturales en conjunción, y al margen, de los criterios oficiales. La necesidad de tierras y el escaso territorio disponible empujó a sus usuarios del siglo XIX con mayores recursos a realizar roturaciones clandestinas en monte público. No creció el número de pequeños propietarios a principios de ese siglo, pero sí el de aquellos que superaban las $10 \mathrm{Has}$. La tendencia fue

Tabla 1

DINÁMICAS TERRITORIALES EN LA SIERRA DE ENGUERA (1580-1930)

\begin{tabular}{|c|c|c|c|}
\hline PERÍODO & RÉGIMEN & GESTIÓN & CONTEXTO \\
\hline $1580-1869$ & $\begin{array}{c}\text { Condominio Municipio- } \\
\text { Señor }\end{array}$ & Ocupación interina & Ruptura Liberal \\
\hline $1870-1905$ & $\begin{array}{c}\text { Municipal, Propietario el } \\
\text { Ayuntamiento }\end{array}$ & $\begin{array}{c}\text { Avance de la } \\
\text { Privatización Individual }\end{array}$ & $\begin{array}{c}\text { Nueva Legislación } \\
\text { Forestal y } \\
\text { Concordia }\end{array}$ \\
\hline $1905-1932$ & Monte de Utilidad Pública & Fijación de enclavados & Deslinde \\
\hline
\end{tabular}

Elaboración propia. 
incrementándose a lo largo del siglo, pues la propiedad de los mayores propietarios fue al alza, con la privatización de importantes superficies de monte público.

En general, aquella gran dehesa de aprovechamientos comunales, de 24.000 Has de extensión, en régimen de empriu (Peset y Hernando, 2001), con un reducido espacio agrario en régimen de explotación privado, que era el término de Enguera al inicio de la octava década del siglo XVI, registró sucesivas dinámicas territoriales, según el régimen de acceso a los recursos naturales (Tabla 1 ).

Que pueden agruparse, según unos determinados contextos, en cuatro períodos:

$1^{\circ}{ }^{\circ} \quad$ (1580-1741): baja densidad demográfica y desarrollo inicial de la industria textil lanera.

$2^{\circ}$ - (1741-1869): alta densidad demográfica y alto desarrollo de la industria textil. Ruptura liberal.

$3^{\circ}$ - (1869-1905): retroceso demográfico e industrial. Concordia para el remate del régimen señorial.

4º (1905-1932): leve recuperación demográfica y bajo nivel industrial. Deslinde de los montes de Utilidad Pública.

Sobre los montes del término se aplicó la legislación forestal de la década de los años 1860, en concreto, la Ley de Montes de 1863 y el Reglamento de 1865. Entre 1870 y 1905, el Ayuntamiento era el propietario de los montes, representando al común de vecinos. La gestión del monte quedaba bajo la tutela del Distrito forestal, donde el Ayuntamiento proponía y la Administración forestal aprobaba los planes anuales de aprovechamiento forestal. Desde 1905 se realiza el deslinde de los montes públicos, catalogados como de Utilidad Pública, delimitándolos respecto de las propiedades enclavadas en éste. La gestión de la parte pública se realizaba como en la etapa precedente.

Los principales actores de las transformaciones paisajísticas operadas en el territorio fueron los vecinos, quienes, mediante acciones individuales como por la actuación y apoyo del Ayuntamiento, transformaron el paisaje a lo largo del dilatado proceso de implantación del régimen liberal en la villa. De tal modo, al hilo del desarrollo del individualismo agrario iniciado durante el siglo XVIII, aparecen nuevas estrategias de apropiación del territorio, que culminan con un incremento sustancial del uso del espacio durante la primera mitad del siglo XIX, tras los cambios propiciados por el primer liberalismo. También se destaca la participación de la casa condal y del propio Estado y de sus administraciones inferiores.

\subsection{Metodología para detectar los procesos}

En cuanto al planteamiento metodológico para la detección de los procesos, es apropiado implementar el siguiente enfoque:

$1^{\circ}$. Análisis de la acción antrópica en un medio natural, con la intención de mostrar la relevancia de la sociedad humana en la organización, estructura y dinámica de los sistemas naturales. Para ello, se requiere efectuar una contextualización social de las fuerzas rectoras que deciden la evolución de los paisajes.

$2^{\circ}$. Por tanto, resulta apropiada la reconstrucción del proceso de crecimiento agrario y la modificación ambiental del territorio a largo plazo, situándolo en su contexto socio-institucional, y analizando los conflictos de intereses en juego, mediante el empleo de diversas fuentes historiográficas de archivo.

A través de algunos procedimientos:

1. Analizar la apropiación del territorio a partir de fuentes catastrales, a las que se deben hacer las necesarias críticas (Pro, 1992, 1996 y 1997), informes de origen señorial y actas de deslinde de montes públicos. Para entender los rasgos «originales» del 
paisaje a mediados del siglo XVIII (1er Padrón de Riqueza), como punto de partida antes del liberalismo, se debe analizar la trayectoria previa, tanto desde un punto de vista natural, como demográfico y socio-institucional.

2. Examinar las transformaciones territoriales y eco-paisajísticas mediante la reconstrucción de los (a)cambios de uso del suelo e identificar las principales (b)fuerzas impulsoras de los cambios de uso del suelo.

Para dar respuesta a ello se pueden obtener, a partir de una amplia gama documental, los datos requeridos mediante el trabajo de archivo, según los siguientes criterios:

a) Qué había sido antes de 1930 cada unidad de paisaje (áreas ecogeográficas: área agrícola y Sierra).

b) Relacionar los factores productivos movilizados por la economía con las capacidades del territorio que le sirve de sostén, para comprender cómo y porqué la acción humana cambia a lo largo del tiempo la configuración del territorio y su funcionamiento ecológico.

Para este fin es conveniente considerar las dimensiones históricas y sociales del problema, con objeto de entender los móviles económicos y los filtros institucionales que rigen los cambios.

Puesto que, tal vez, la adaptación ambiental de la sociedad radica en maximizar las satisfacciones que busca en el área cultural y minimizar los esfuerzos que invierte en ello. De modo que, resulta apropiado examinar la interconexión entre bases físicas y jurídicoinstitucionales e ideológicas, a partir de la cual se crean espacios multiuso, o paisajes, en un ambiente ecológico determinado, mediterráneo en este caso, cambiantes según las necesidades de la sociedad.

\section{DETERMINACIÓN DEL ESPACIO GEOGRÁFICO A PARTIR DE LOS PRO- CESOS SOCIALES}

1. En Enguera se distinguen dos grandes áreas o modelos de uso del territorio: la Redonda (6.000 Ha) y la Sierra (18.000 Ha) (Figura 1). Esta distinción es acorde con la base física en que se desarrolla y con el modelo territorial implantado en el siglo XIII - realengo, evolucionando a encomienda de orden militar, que se señorializó por venta de la jurisdicción a finales del siglo XVI- que llegó hasta la ruptura liberal del siglo XIX, y que determinó el régimen de acceso a los recursos naturales. El nuevo señorío desplegado en Enguera entre 1580 y principios del siglo XIX, fue un señorío eminentemente jurisdiccional. El poder señorial quedaba limitado mediante el ejercicio de los poderes que el rey se reservaba en calidad de señor supremo y con el contrapeso de la confirmación de los privilegios locales, que recortaban desde abajo las atribuciones señoriales. ${ }^{6}$ En consecuencia, en el interior del nuevo estado existía un dominio fraccionado, con las consiguientes limitaciones de dominio. Posteriormente, con el desarrollo del liberalismo local se reordenó el territorio bajo otros criterios.

2. El proceso de apropiación del territorio se verá afectado por la industria textil, en tanto que alternativa económica en el municipio, pues reducía el uso agrario del espacio inmediato (Hernández Marco, 1976, 1980 y 1987). Sin embargo, cuando sobrevino la crisis industrial a mediados del siglo XIX, no llegó a provocar una presión agrícola sobre el entorno rural del municipio tan grande como cabía esperar. Ello fue debido a que en ese período se desplegó el tendido ferroviario y se produjo 


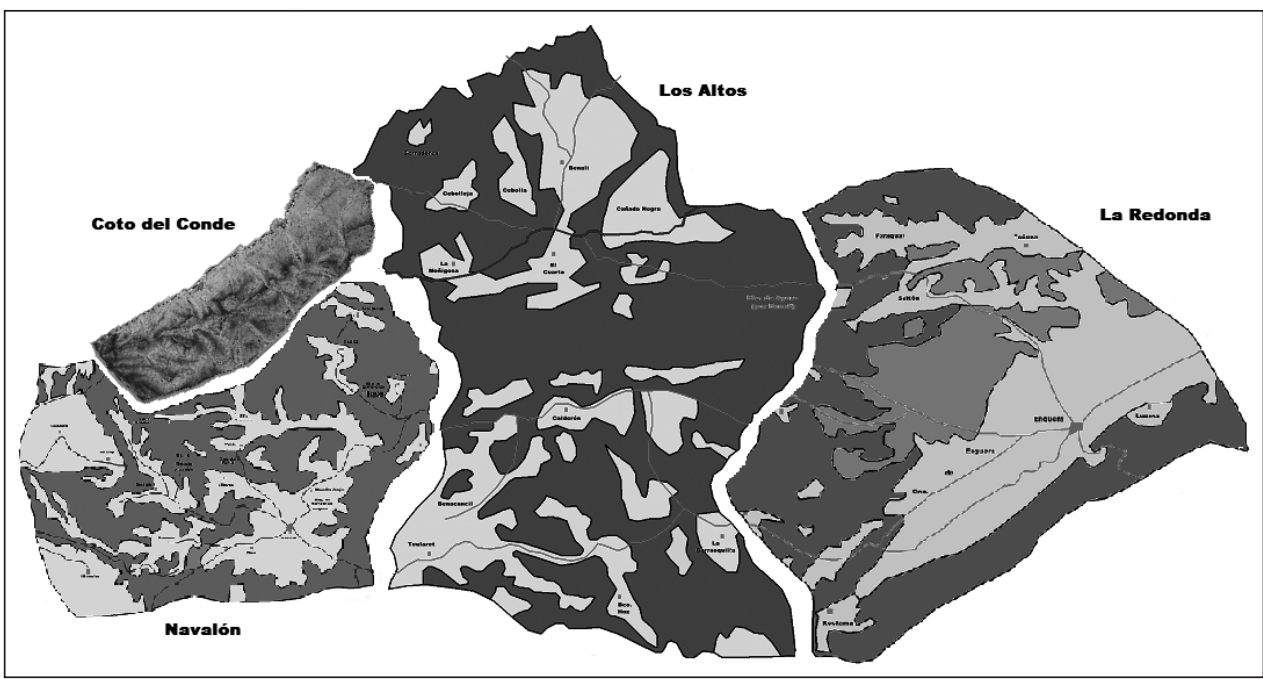

FIGURA 1. Croquis del término municipal Enguera fraccionado según el catálogo de montes de utilidad pública (1905) y del monte particular denominado Coto del Conde (1870). Elaboración propia.

NOTA: Las tonalidades en grises claros corresponden a las áreas roturadas en los montes Navalón, Los Altos y La Redonda.

la integración de los mercados hacia 1860-1900. Además, este hecho enlazó con la política forestal del Estado que terminó con la inclusión de los montes de Enguera entre los de Utilidad Pública, en proceso de deslinde desde 1905 hasta 1932, y que estrechó definitivamente el margen para realizar los aprovechamientos comunes tradicionales.

3. En la Vall de Enguera (Figura 2), el espacio agrario, estaban ya representadas en 1580, según el núcleo de tierras propiedad - vendidas paulatinamente a particulares - de la Orden, situadas en el centro, una variada gama de producciones agrarias, a base de cultivos de rendimiento aplazado y de cereales. Las principales innovaciones productivas registradas a finales del siglo XVIII son el maíz de secano en el valle, gracias a las potencialidades edáficas y a la técnica de cultivo utilizada, y la vid en la zona circundante. El expediente de supresión del bovalar de 374 Has en 1793, confirma que se estaba registrando en esta zona un crecimiento agrario basado en cultivos arbóreos y arbustivos, además del cereal, ya constatado en 1741 y que se acentúa hasta 1838 y 1884, cuyas producciones estaban siendo progresivamente absorbidas por los mercados, siguiendo en parte la tradición agronómica del siglo XVI.

En 1884 la superficie cultivable de propiedad particular en la Redonda sumaba 2.478 Hectáreas, el $37 \%$ de la superficie de esta demarcación, de las que 1.638, el 66\% se localizaban en la Vall. A comienzos del siglo XX, se había incrementado el cultivo en poco más de 100 Hectáreas en el conjunto de la Redonda. En ese momento, presentaba un grado de afección antrópica que superaba el $60 \%$ de su extensión, entre cultivos leñosos y herbáceos $(42 \%)$ y monte roturado $(18 \%)$.

4. Las dehesas de la sierra, Albarrella y Argoya [Monte Navalón] (Figura 3), fueron vendidas en 1621 por el señor útil y propietario que las detentaba, primero la Encomienda de Enguera, después D. Bernabé de Borja, señor de Enguera y Anna. Esta 


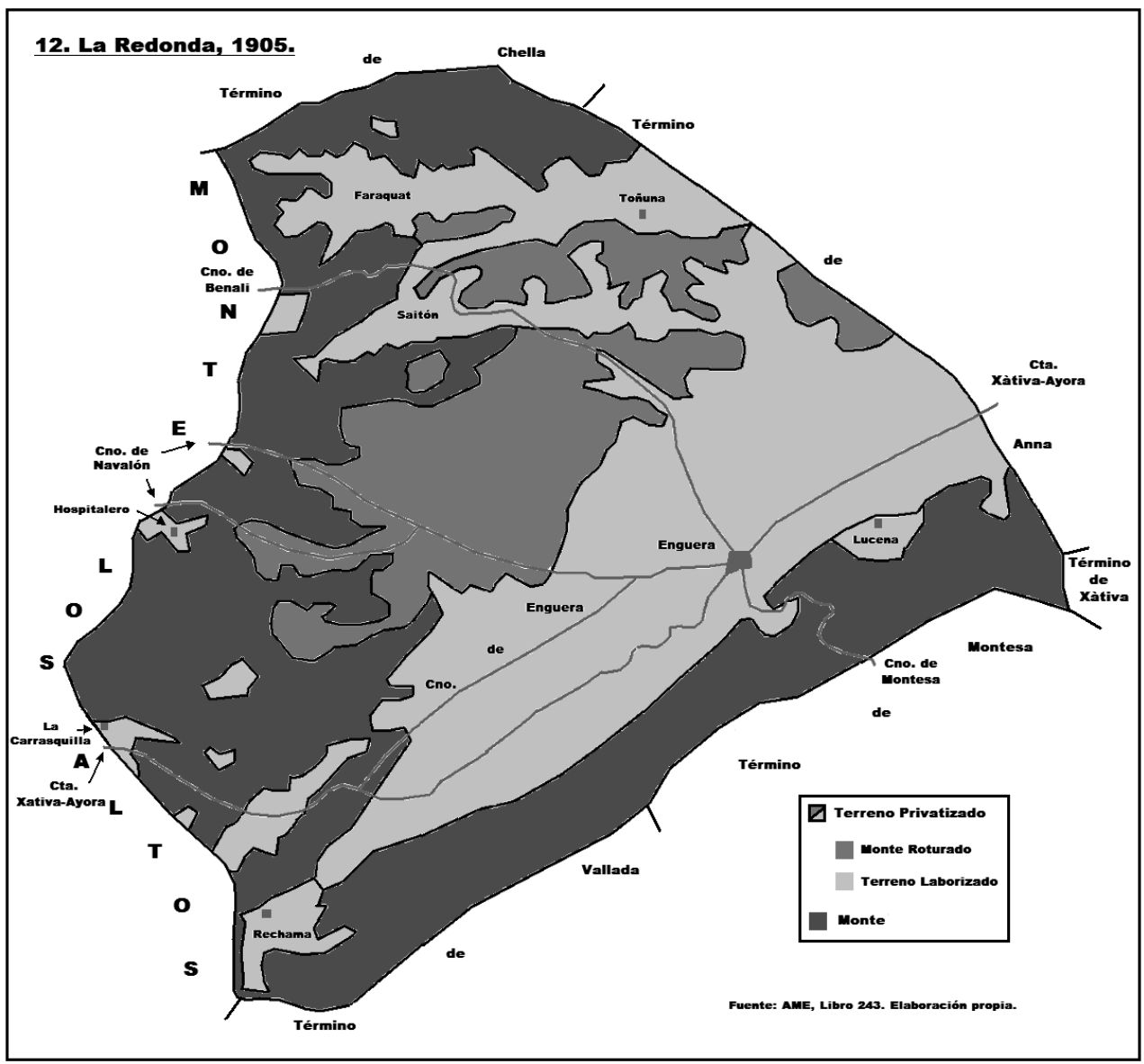

Figura 2. Monte de La Redonda (1905).

transacción particular se unió a otras propiedades privadas colindantes que ya existían con anterioridad. Antes de la venta, el señor directo y útil cedía la explotación de estos espacios a cambio del diezmo sobre lo producido y de un canon en metálico por su utilización, el terrazgo. Aunque, pretendió instaurar el contrato enfitéutico en la zona, sin conseguirlo [1602, intento de comiso a Tomás García (partida de Santich), éste respondió que pagaba censo en metálico, sin luismo ni fadiga; se dio la razón a García]. A mediados del siglo XVIII, se aprecia un incremento del uso agrario del amplio territorio circundante, que se intensificará a lo largo de la segunda mitad de la centuria. Al parecer, los mecanismos de apropiación en esta zona fueron parecidos a los empleados en la privatización de las tierras propiedad de la orden en la Vall, que fueron vendidas progresivamente a particulares, tal vez antiguos arrendadores. Pero la diferencia en la Sierra estriba en que los nuevos propietarios pudieron arrancar pedazos al dominio del señor y al aprovechamiento del vecindario, por una parte, y usar de forma interina el inculto, por otra, ya que los límites de las parcelas no estaban tan bien definidos como en la zona agraria. 


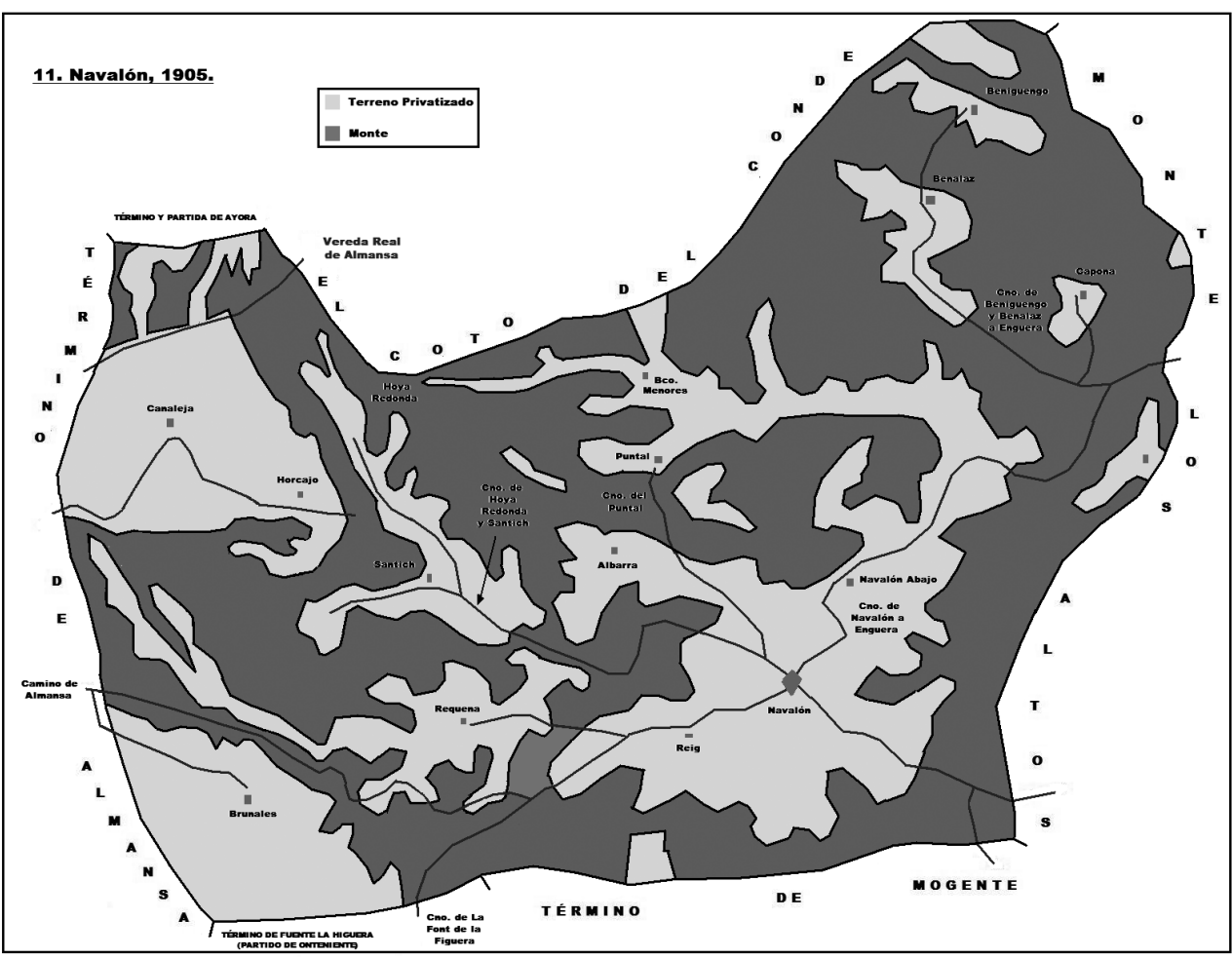

FIGURA 3. Monte Navalón (1905).

Fuente: AME, libros 1.085 y 1.086. Elaboración propia.

5. En general, el régimen de condominio sobre los montes de Enguera pudo ser la clave explicativa del avance de la apropiación del territorio en las afueras de la Redonda, realizada de forma particular, irregular y a la romana -individual y sin restricciones-. Esta es una situación muy parecida a la que se registra en zonas de realengo, en las que se contaba con un alto grado de maniobra en cuanto al uso del territorio. El proceso guarda ciertas semejanzas con lo sucedido en las tierras bajas de las provincias de Barcelona y de Girona (Pere Sala, 1998), aunque allí parece que fue en una fase temporal anterior.

Las apropiaciones individuales se registraban en los Padrones de Riqueza y contribuían a la hacienda municipal. A finales del siglo XVIII, se localizan preferentemente cerca de las principales vías de comunicación, lo cual permite sospechar que, en esta fase temporal, se fueron buscando las tierras más fértiles con mejor accesibilidad en un contexto de baja densidad demográfica y de una importante alternativa económica facilitada por la industria textil.

Existió la posibilidad de extender el uso agrario entre 1741 y 1838 (Figuras 4 y 5). Al parecer, una especie de frente antirroturador, formado por la oligarquía local -industrial, ganadera y agraria - y la administración señorial, pudo ralentizar la utilización del potencial agrario en Enguera durante el Antiguo Régimen. Los 


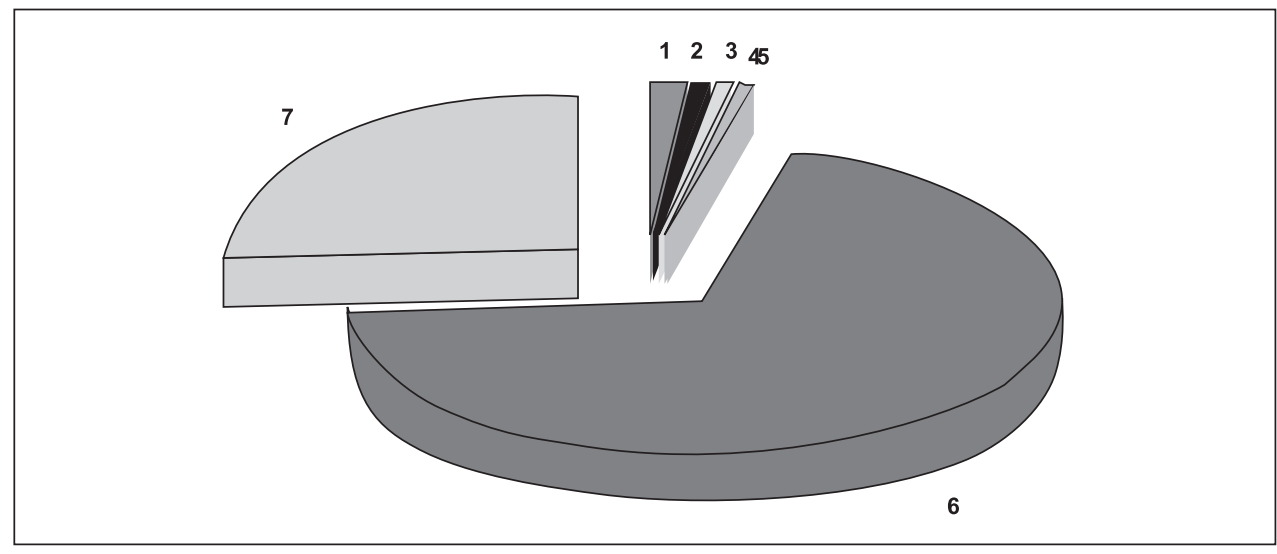

Figura 4. Usos del suelo en 1741.

FUENTE: Hernández Marco (1980). Elaboración propia.

NOTA: 1: Cereales; 2: Viña; 3: Olivo; 4: Otros; 5: No especificados; 6: Prados, montes y bosques; 7: Superficie improductiva. La superficie de prados, montes y bosques ha sido obtenida al restar de la superficie total actual la superficie cultivada, siguiendo una sencilla propuesta metodológica del G.E.H.R., recogida por Garrabou (1985). La superficie improductiva se compondría por la extensión ocupada por los caminos y veredas, barrancos y cauces de ríos, edificaciones, etc., tal vez un 15\% del territorio municipal (Hernández Marco y Romero González, 1980:41), aunque en el caso de Enguera, según las características geomorfológicas de la zona, es posible considerar que el terreno improductivo puede alcanzar el $30 \%$ del territorio municipal, tal como se ha estimado para la media europea (Tello, 2004:67).

balances entre los estímulos y los obstáculos al crecimiento tendieron a ser menos favorables a los primeros a medida que el modelo de crecimiento agrario encontró limitaciones ambientales, pues se requería el uso de gran cantidad de suelo que empezó a escasear a finales del siglo XVIII, como demuestra la el cambio de uso definitivo en 1793 en el antiguo bovalar. Además de resistencias institucionales y políticas, como en la Baja Andalucía (actitud anti-roturaciones, pro-ganadera). Finalmente, el alza de los precios agrícolas al final del siglo XVIII, el aumento de la presión fiscal y el endeudamiento colectivo del municipio, pudo disparar la carrera hacia la privatización de espacios de titularidad colectiva (Tabla 2).

6. Como en la etapa anterior, durante el siglo XIX, y a principios del siglo XX, la extensión del área cultivada a costa del monte se realizaba, siguiendo la coyuntura de precios, de manera fugaz, interina, bonificando parcelas a base de hormigueros para obtener buenas cosechas aprovechando la feracidad del suelo en un contexto de baja presión demográfica. Disminuida la fertilidad, se abandonaba la parcela al monte, consiguiendo así una regeneración natural de los nutrientes. Esta es una característica fundamental del uso de la Sierra de Enguera, muy acorde con las características ambientales de la zona.

El Ayuntamiento solamente tenía atribuciones para conceder licencias de roturación de tierras incultas en el ámbito de la Redonda. Pero consintió la roturación de parcelas de monte a lo largo de la primera mitad del siglo XIX, cuando tuvo potestad para ello, siguiendo los vaivenes del proceso de implantación del Régimen Liberal en el municipio. El señor no podía concederlas en su ámbito jurisdiccional, la Sierra, pues en este territorio prevalecía un régimen de condominio con los vecinos. 
Por ello, allá donde pudo, pues sus competencias jurisdiccionales se lo permitían, la casa señorial concedió establecimientos, caso de Anna y Elda. Por tanto, quien consolidó en coyunturas concretas, desde 1811, las roturaciones sin permiso fue el Ayuntamiento.

Un análisis de los usos del suelo en 1838 advierte del importante incremento de la tierra dedicada al cereal (12\% de la superficie municipal) y de la viña. Favorecieron esta expansión tanto las reformas institucionales como la dinámica del mercado. Contribuyó, también que entre 1741 y 1857 la población dispuso de territorio suficiente para obtener la energía necesaria para su mantenimiento ( $2 \mathrm{Ha} /$ habitante). La superficie cultivable, pese a incrementarse, mantuvo relaciones muy bajas respecto al número de habitantes, con lo que se puede sospechar, desde esta perspectiva, que la economía local estaba dominada por el sector manufacturero, así como, a nivel interno del sector agrario, una desigual distribución de la tenencia y uso de la tierra de cultivo.

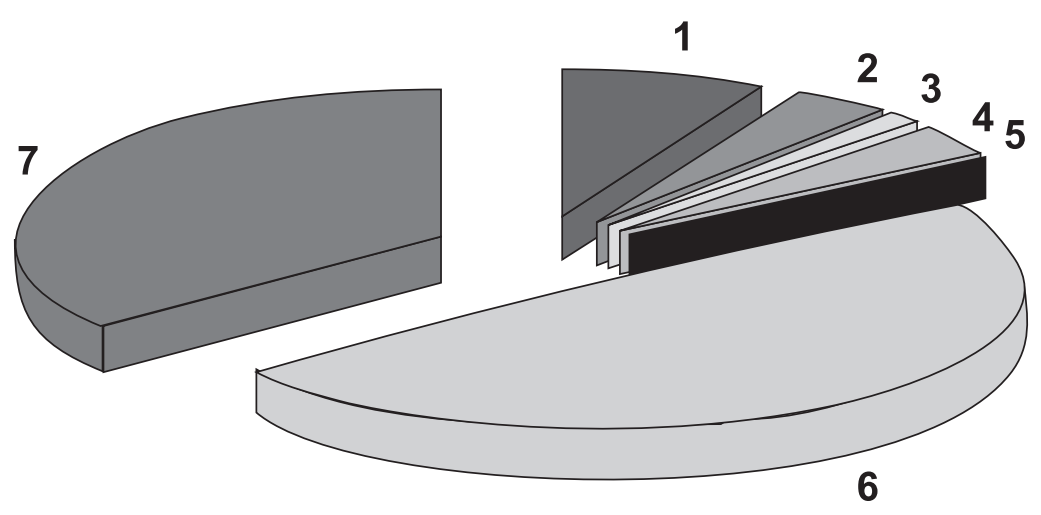

Figura 5. Usos del suelo en 1838.

FUENTE: Hernández Marco (1980). Elaboración propia.

NOTA: 1: Cereales; 2: Viña; 3: Olivo; 4: Otros; 5: No especificados; 6: Prados, montes y bosques; 7: Superficie improductiva.

Tabla 2

COMPARACIÓN DE LOS USOS DEL SUELO EN 1741 Y 1838 (HECTÁREAS Y \%

\begin{tabular}{|c|c|c|c|c|c|c|}
\hline & \multicolumn{2}{|c|}{ Cultivos } & \multicolumn{2}{c|}{$\begin{array}{c}\text { Bosques, eriales e } \\
\text { improductivo }\end{array}$} & \multicolumn{2}{c|}{ Total } \\
\hline AÑN & 1741 & 1838 & 1741 & 1838 & & \\
\hline TOTAL & 1.127 & 4.069 & 22.898 & 19.956 & 24.025 & 24.025 \\
\hline$\%$ & 4,7 & 16,9 & 95,3 & 83,1 & 100 & 100 \\
\hline
\end{tabular}

FUENTE: Elaboración propia a partir de Hernández Marco (1980). 
7. El conde de Cervellón consiguió en 1844 que los tribunales le otorgaran la posesión absoluta de la Sierra, al amparo del Decreto de 1837, aprovechando el control de las instituciones por sectores afines a su ideología. Era un intento de transformar los derechos señoriales en propiedad privada, en un contexto de cambios que apoyaba la propiedad particular. Pero, los vecinos interpusieron una demanda en 1846, apoyada en el régimen de condominio sobre la Sierra. Entre tanto, los montes quedaron exceptuados de la desamortización liberal, por constituir una propiedad privada desde 1844 a 1870 y desde ese año en adelante por las cláusulas precautorias que se incluyeron en la concordia (si el Estado quisiera desamortizarlos porque habían pasado al Ayuntamiento, revertirían al conde, su titular por la Sentencia de 1867). Evidenciando el carácter mutable de la propiedad, fue relevante la participación de los individuos en la definición de la nueva propiedad. De este modo, ante un panorama de déficit de territorio y, en un marco político que propugnaba la extensión de los usos agrarios, las posibilidades de implementar una transformación ambiental, y de dominio en algunos casos, parece que tuvieron relativo éxito por parte de la comunidad rural de Enguera (Figura 6). La privatización del monte público se produjo según los intereses y estrategias de los grupos sociales presentes en la villa, en función de sus aspiraciones, relacionada con las características y posibilidades productivas de la sociedad en la que se desenvuelven y con la posición que ocupan. Así, de la roturación se benefició de forma desigual el heterogéneo grupo de vecinos, en mayor medida a raíz de los cambios institucionales operados en España a partir de la primera mitad del siglo XIX.

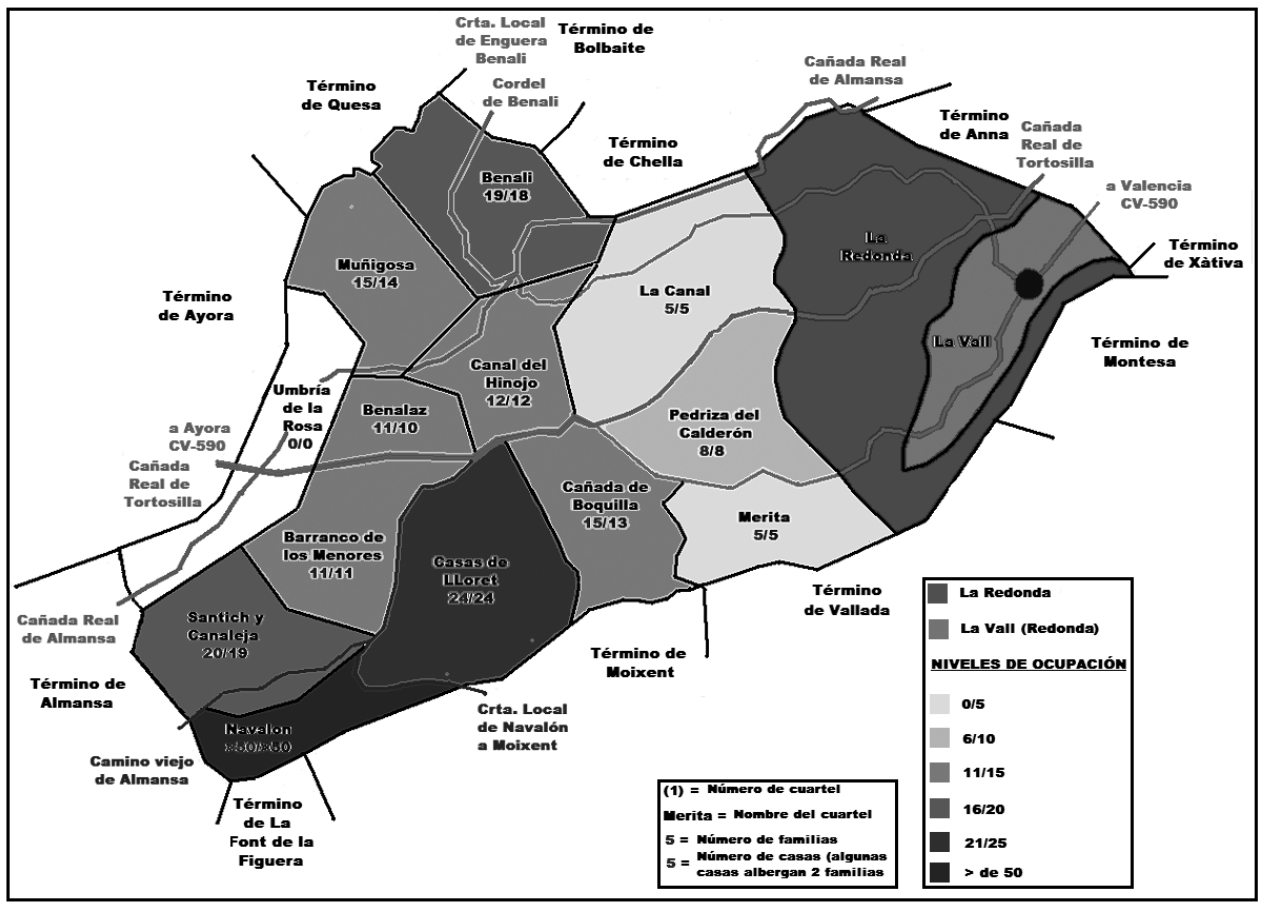

FIGURA 6. Distribución de la Sierra por cuarteles, 1869. 


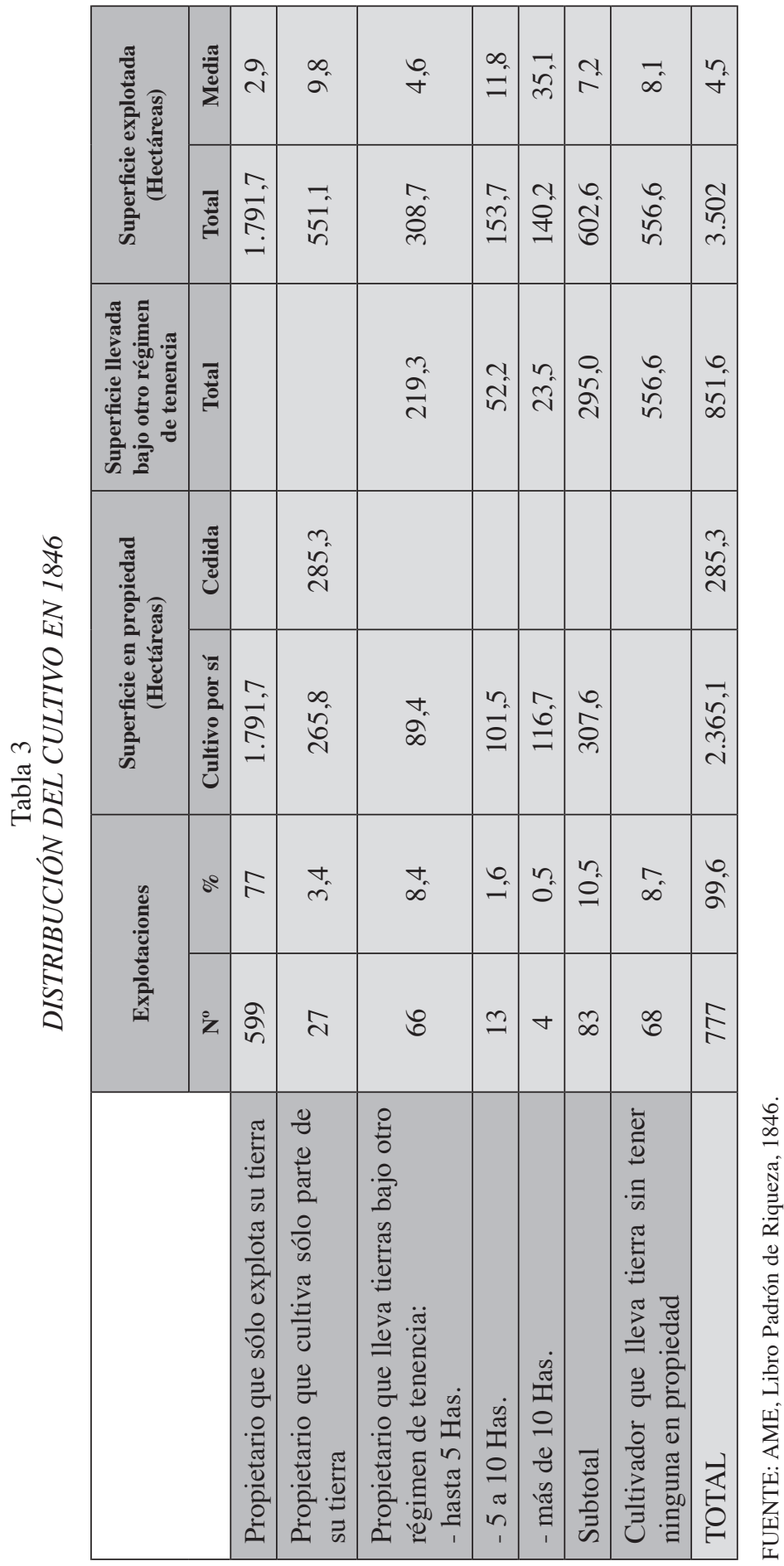


En dicho período, las roturaciones permitieron el acceso a la propiedad a pequeños cultivadores en un espacio montañoso, a menudo con permiso de la corporación municipal. Otros agentes, mejor dotados de recursos, transformaron en mayor medida el territorio. En ambos casos, se aprovecharon en esta etapa de transición al liberalismo circunstancias y coyunturas en que la señoría se encontró en posiciones de debilidad para progresar en la tendencia a la privatización. Todavía en 1854 el sector industrial condicionaba al sector agrario de Enguera, que mostraba un predominio de pequeños propietarios. Sin embargo, en 1884, cuando retroceda el sector industrial, se constata otro modelo de distribución de la propiedad territorial caracterizado por un incremento en la polarización entre pequeños y grandes propietarios, muchos de éstos con importantes superficies de monte privado.

8. A mediados del siglo XIX la modalidad de explotación agraria predominante es el cultivo directo. Se advierte con claridad el carácter híbrido de la economía local, pues las distintas orientaciones productivas estaban en estrecha relación. La industria presentaba una gran capacidad de absorción de trabajadores, los cuales podían compatibilizar bien esta actividad con una pequeña agricultura, de manera que la pluriactividad les situaba en una posición distinta a la de los jornaleros netos. Sin olvidar que el uso de amplios espacios continuaba abierto a los vecinos durante el siglo XIX (Tabla 4).

Tabla 4

EXPLOTACIONES AGRARIAS EN 1846

\begin{tabular}{|c|c|c|c|c|}
\hline \multirow{2}{*}{$\begin{array}{c}\text { NIVELES } \\
\text { (Hectáreas) }\end{array}$} & \multicolumn{2}{|c|}{ CULTIVADORES } & \multicolumn{2}{c|}{ SUPERFCIE } \\
\cline { 2 - 5 } & Número & $\%$ & Hectáreas & $\%$ \\
\hline Hasta 0,5 & 192 & 24,2 & 70 & 2,1 \\
\hline $0,5-1$ & 132 & 16,6 & 109 & 3,1 \\
\hline $1-2$ & 135 & 17,1 & 210 & 5,9 \\
\hline $2-3$ & 83 & 10,4 & 213 & 6,1 \\
\hline $3-4$ & 44 & 5,5 & 161 & 4,6 \\
\hline $4-5$ & 27 & 3,4 & 127 & 3,6 \\
\hline $5-10$ & 94 & 11,8 & 716 & 20,4 \\
\hline $10-30$ & 73 & 9,2 & 1.148 & 32,7 \\
\hline $30-50$ & 4 & 0,5 & 163 & 4,6 \\
\hline Más de 50 & 7 & 0,8 & 585 & 16,6 \\
\hline TOTAL & 791 & 99,5 & 3.502 & 99,7 \\
\hline
\end{tabular}

FUENTE: AME, Libro Padrón de Riqueza, 1846.

En 1846 la distribución de la tierra de cultivo desde la perspectiva de las explotaciones no modifica la desigual distribución de la propiedad (Tabla 5). La explotación agrícola «suficiente» estaría comprendida entre las 12 y las 30 Hectáreas, de modo que, en ese año, la mayor parte de las explotaciones registradas se situaban por debajo de este umbral, pero gestionaban algo más del $50 \%$ de la tierra de cultivo. 
La integración entre los espacios agrícola, pecuario y forestal resulta determinante para la eficiencia de este sistema agrario, a pesar del alto costo en territorio que supone. La relativa pobreza de recursos hacía necesaria este modo de integración para obtener un cierto nivel de intensificación, en un sistema agrario que emplea tanta mano de obra en extensiones insuficientes. Existían algunas grandes explotaciones conformadas exclusivamente con tierras ajenas, cuya cesión evidencia una estrategia adaptativa por parte de los propietarios a las cambiantes circunstancias agrarias para captar mejor las tendencias de precios alcistas, lo que supone una esmerada lógica económica. Una aproximación a la gestión del mayor propietario agrario entre 1838 y 1854, revela que se realizaba de un modo flexible en el tiempo, adoptando el cultivo directo o indirecto (asistido). También flexible en el espacio, pues se adecuaban las explotaciones a las circunstancias de cada territorio en que se ubicaban, el valle o la Sierra, conformando unidades dispersa y fraccionadas hasta la parcela, en la primera área, o concentradas e integradas, en la segunda.

Tabla 5

COMPARACIÓN ENTRE PROPIEDAD Y EXPLOTACIÓN EN ENGUERA: 1846

\begin{tabular}{|c|c|c|c|c|c|c|c|c|}
\hline \multirow{2}{*}{ HAS } & \multicolumn{4}{|c|}{ PROPIEDAD } & \multicolumn{4}{c|}{ EXPLOTACION } \\
\cline { 2 - 10 } & Propietarios & $\%$ & Has & $\%$ & Cultivadores & $\%$ & Has & $\%$ \\
\hline Hasta 5 & 644 & 79,1 & 932 & 26,6 & 613 & 77,5 & 890 & 25,4 \\
\hline $5-10$ & 92 & 11,3 & 695 & 19,8 & 94 & 11,8 & 716 & 20,4 \\
\hline $10-30$ & 66 & 8,1 & 1.010 & 28,9 & 73 & 9,2 & 1.148 & 32,7 \\
\hline Más de 30 & 12 & 1,4 & 857 & 24,5 & 11 & 1,3 & 748 & 21,3 \\
\hline TOTAL & 814 & 99,9 & 3.494 & 99,8 & 791 & 99,8 & 3.502 & 99,8 \\
\hline
\end{tabular}

FUENTE: AME, Libro Padrón de Riqueza, 1846.

9. A lo largo de las décadas centrales del siglo XIX parece disminuir la superficie de uso agrario, al tiempo que el dato de 1884 muestra una recuperación respecto a la etapa precedente (Figuras 7 y 8). Esta disminución en los datos de 1846 y de 1854 puede estar directamente relacionada con una ocultación deliberada, ya que desde 1844 el conde dispuso del dominio pleno de los montes de Enguera. No cuadra que el descenso en el uso del territorio se desarrolle en una época de fuerte crecimiento demográfico (en 1860 se alcanza el techo demográfico en el período de este estudio con 6.834 habitantes). Por su parte, la recuperación de 1884 se inscribe en una fase demográfica negativa, iniciada en la década de los años 1860, caracterizada en el tramo final del siglo por una fuerte corriente emigratoria. En consecuencia, cabe pensar que hubo una reconversión en el modo de uso del territorio, ligado al mercado. Un ejemplo paradigmático de estas nuevas conductas es la finca Cañada Negra [compras además de usurpación consentida por el ayuntamiento y Gobierno civil].

Matiza la información de los catastros hacendísticos locales, que registran parcialmente la realidad, el Informe sobre la Sierra de Enguera de 1869, elaborado a instancias del conde de Cervellón. A partir de la información que contiene, se puede sostener que la disminución registrada en las décadas centrales del siglo XIX en los catastros estaría directamente relacionada con el estilo en que se usaba el territorio 
en Enguera, pues el terreno labrado no es permanente en todo tiempo y espacio, sino que unas veces se abandona al monte y otras el monte se labra. Este vaivén escaparía a los registradores de la propiedad y a los que elaboraban los Padrones de Riqueza como base para recaudar impuestos, por lo que solamente se registraría la superficie agraria útil, pues del monte era dueño el conde, en cada ejercicio económico. De la visura que realizó de la Sierra, el ingeniero que redactó el citado informe ratificó que se habían registrado tantas roturaciones y se había establecido tanta población que éstos estaban en posesión de hecho de una grandísima parte de la misma convertida en terreno labrantío.

10. Al mismo tiempo que perdía fuerza el sector textil local, sin que se llegara a alcanzar un estadio de desindustrialización, el número de habitantes de Enguera se redujo a lo largo de la segunda mitad del siglo XIX, lo que potenció el uso agrario, ganadero y forestal del territorio como alternativa económica. Las actas municipales de la década de los años 1880 condenan los abusos cometidos por la población diseminada en la Sierra, que erosionaban los aprovechamientos públicos gestionados por el ayuntamiento al roturar terrenos y talar pinos para elaborar carbón vegetal. Al parecer, mientras el gobierno central autorizaba las cortas de pinos en los planes de aprovechamiento elaborados por el consistorio, no hubo quejas. Éstas se producían cuando se negaban, generando reacciones en contra (talas ilegales, incendios provocados) permitidas por el alcalde. La evolución de los mercados del vino y de la madera en este período pudieron absorber las pérdidas en el sector textil, propiciando la transformación de los usos del territorio. La población de Enguera dependía en mayor medida de la agricultura y privatizaron una mayor cantidad de tierra, apoyados en la gran libertad que tuvieron para roturar. Se estaban consolidando dos vías agrarias frente a la crisis industrial, una relacionada con la subsistencia y otra ligada a la evolución del mercado.

11. El deslinde de los montes de Utilidad Pública destapa que a principios del siglo XX eran pocos los que poseían títulos de propiedad, aunque figuraban en los amillaramientos y pagan contribución. Las fincas englobaban monte. Por ello, en numerosas ocasiones el deslinde supuso una reordenación del espacio que se había estructurado bajo otros criterios. Se constataba que la utilización del territorio había sido mayor de la que les otorgaba a sus propietarios los títulos de propiedad, cuando los tenían. Aunque estaban obligados a ello quienes no justificaran la propiedad, parece que no

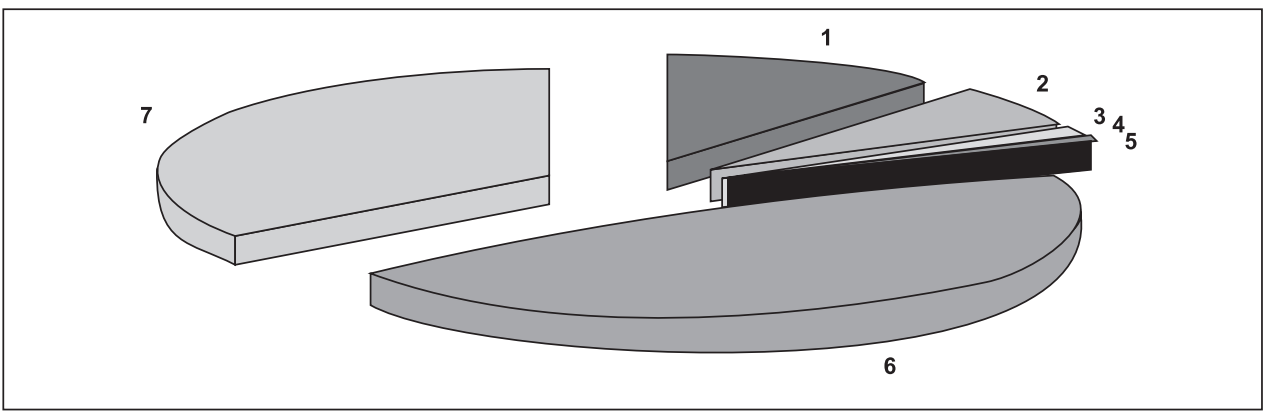

Figura 7. Usos del suelo de Enguera en 1884.

FUENTE: AME, Amillaramiento, año 1884.

NOTA: 1: Cereales; 2: Viña; 3: Olivo; 4: Otros; 5: No especificados; 6: Prados, montes y bosques; 7: Superficie improductiva. 


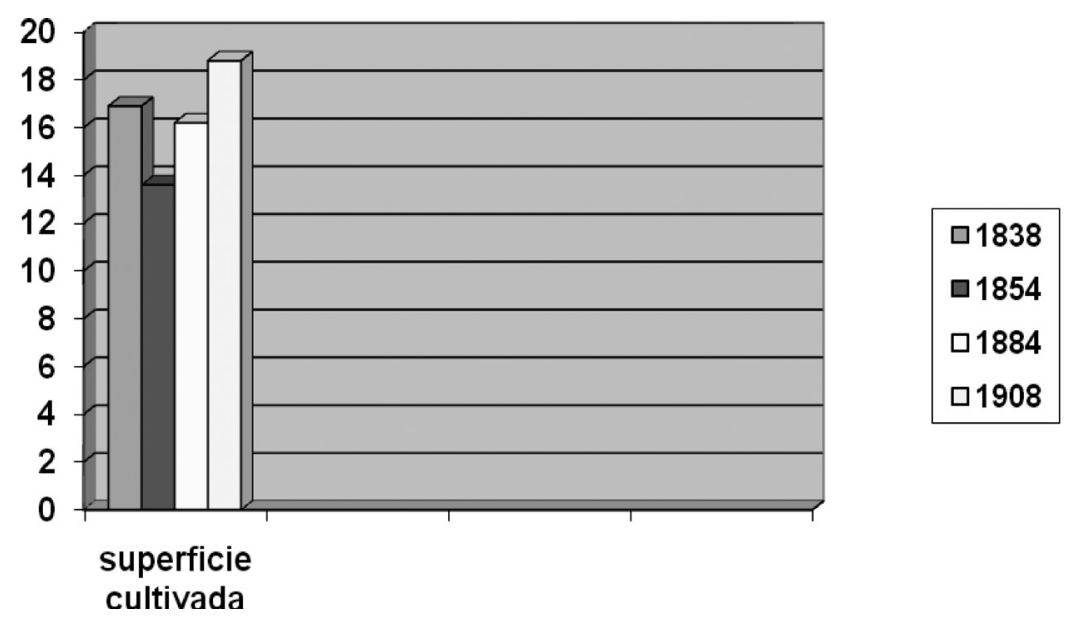

FIGURA 8. Evolución porcentual de la superficie cultivada entre 1838 y 1908.

FUENTE: AME, Padrón de Riqueza, año 1838; Padrón de Riqueza, año 1854; Amillaramiento, año 1884; Deslinde de los montes La Redonda y Navalón, año 1908. Queda por contabilizar en 1908 el terreno cultivado en el monte Los Altos.

se retornaron al monte la superficie que debió hacerlo. La actitud del Ayuntamiento parece que fue favorable a los intereses de los particulares. Así, el proceso de privatización y de modificación de las pautas de gestión del monte público habría que situarlo en el contexto de la articulación entre las políticas generales y los intereses locales, actuando éstos a tenor de las señales dadas por los mercados (GEHR, 1994, 1999 y 2002). En Enguera eran contados los vecinos que no poseían una roturación, lo que supone una auténtica «vía campesina» de acceso a la tierra.

12. El nuevo carácter que adquiere la propiedad del territorio, a lo largo de la segunda mitad del siglo XIX, se manifiesta al delimitarse los derechos que asisten al municipio de Enguera. Éste decía tener derechos inmemoriales sobre los montes de Enguera, que nadie le disputaba en el monte denominado la Redonda, pero que un sector del vecindario le cuestionaba en los otros montes. Sin embargo, sobre éstos no tenía otro derecho que el que le otorgaba la escritura de Concordia de 1870. De modo que el Ayuntamiento no pudo cumplir lo dispuesto en el Real Decreto de 11 de noviembre de 1864, lo que demostraba que entonces no tenía esos derechos inmemoriales y por eso no inscribió los montes en el Registro de la Propiedad, pues detentaba el dominio útil, según la concordia de 1870, cuando quedaron precisados los derechos de ambas partes en litigio. No obstante, afirmar que en los montes de Enguera no podía haber más propiedades que la de aquellos terrenos que fueron legitimados, tenía un punto de debilidad en el hecho de que la escritura de Concordia de 1870 no fue sancionada por la Superioridad. En cambio, se fundamentó en los preceptos contenidos en las leyes municipal y provincial entonces vigentes, de 21 de octubre de 1868, las cuales, según el parecer de la Corporación, autorizaban dicha clase de pactos sin intervención del Gobierno.

A pesar de los deslindes, las ocupaciones de terrenos públicos continuaron efectuándose en la década de los años 1930. Unas veces controladas por la Administración, 
caso de la Orden del Ministerio de Agricultura de 22 de octubre de 1932, que originó la apertura de un expediente municipal ante las solicitudes presentadas por algunos vecinos. También, se seguían registrando roturaciones arbitrarias, que tratan de legalizar algunos vecinos acogiéndose al Decreto del Ministerio de Agricultura de 30 de enero de 1935. Otro proceso de remodelación territorial nace de un expediente municipal de permuta de terrenos según el Real Decreto de 17 de octubre de 1925.

13. La población diseminada supone un modelo específico de ocupación del territorio. Este modo de habitar se iniciaba con la construcción de una casa y el laboreo de una pequeña porción de terreno, la más llana e inmediata al edificio o a alguna fuentecita. El proceso de transformación territorial cobraba intensidad cuando, por las necesidades de la familia, los desmontes se iban separando de la casa. Pero como éstos no podían hacerse sin solución de continuidad, sino salteados en los puntos en que el terreno lo permitía, bien pronto el radio de cada casa abarcaba una extensión considerable. Con las transmisiones hereditarias, la heredad se partía formalmente entre los herederos, poniéndole por límites no los de las tierras verdaderamente labradas, sino todo el terreno que en junto abrazaban, incluyendo la parte de monte que quedaba entre éstas en donde el ganado de todas clases apacentaba durante todo el año (recuerda el modelo de aprisión en Catalunya). Las particiones hereditarias conllevaban nuevas edificaciones de viviendas, y así se formaron grupos de casas, cortijadas, aldeas y hasta pueblos como eran Santich, Benali y Navalón, estos dos últimos con su vicario eclesiástico y su alcalde pedáneo.

Durante la primera parte del siglo XIX parece registrarse una proliferación de casas dispersas. En la segunda mitad del siglo el crecimiento debió resultar vigoroso, pues desde 1850, en treinta años, se pobló la Sierra en proporciones nunca antes alcanzadas. La tendencia continuará hasta concluir el primer tercio del siglo XX, siguiendo una evolución en paralelo a la crisis de la industria textil.

Cuando se está iniciando una intensificación del poblamiento diseminado, un reconocimiento de los montes de Enguera en 1865 muestra que, en el interior del perímetro examinado, existían «unas» 5.000 hectáreas «reducidas a cultivo»; otras 1.500 arrasadas por el fuego en «años pasados»; el restante monte era «monte bajo», con pinos no muy abundantes, aislados y en rodales. El arbolado estaba comprendido entre «la primera y la segunda edad». En consecuencia, la masa forestal estaba relativamente degradada. En conjunto, el territorio roturado (27\%) y las áreas incendiadas (8\%) suponían el $35 \%$ de estos montes.

14. La evolución de la finca La Matea, situada en el interior del Coto del Conde (Figura 9), surgido tras la Concordia entre éste y el municipio en 1870, es un buen ejemplo para evidenciar tanto las dificultades en el proceso de establecimiento del modelo de la «propiedad perfecta», como un ejemplo del modo en que produjeron distintos procedimientos de transformación del paisaje por parte de una amplia diversidad de agentes. Se comprueba que el «triunfo» de la condesa no supuso la «derrota» de los vecinos de Enguera, que habían ocupado el monte.

La presencia de una importante población rural instalada en la Sierra en la década de 1860 convertía en ilusoria la idea de convertir este territorio en propiedad privada del conde. Un medio para frenar el progreso de la población rural diseminada era aplicar la normativa forestal vigente, pues el artículo $5^{\circ}$ de las Ordenanzas de Montes de 1863 «en caso alguno puede aplicarse con más exactitud que al de Enguera», según el asesor personal del conde ya que establecía que quedaban dependientes de la guarda y conservación de la Dirección General los montes en que los pueblos tengan condominio o comunidad de disfrutes o usos con otro propietario. En este 


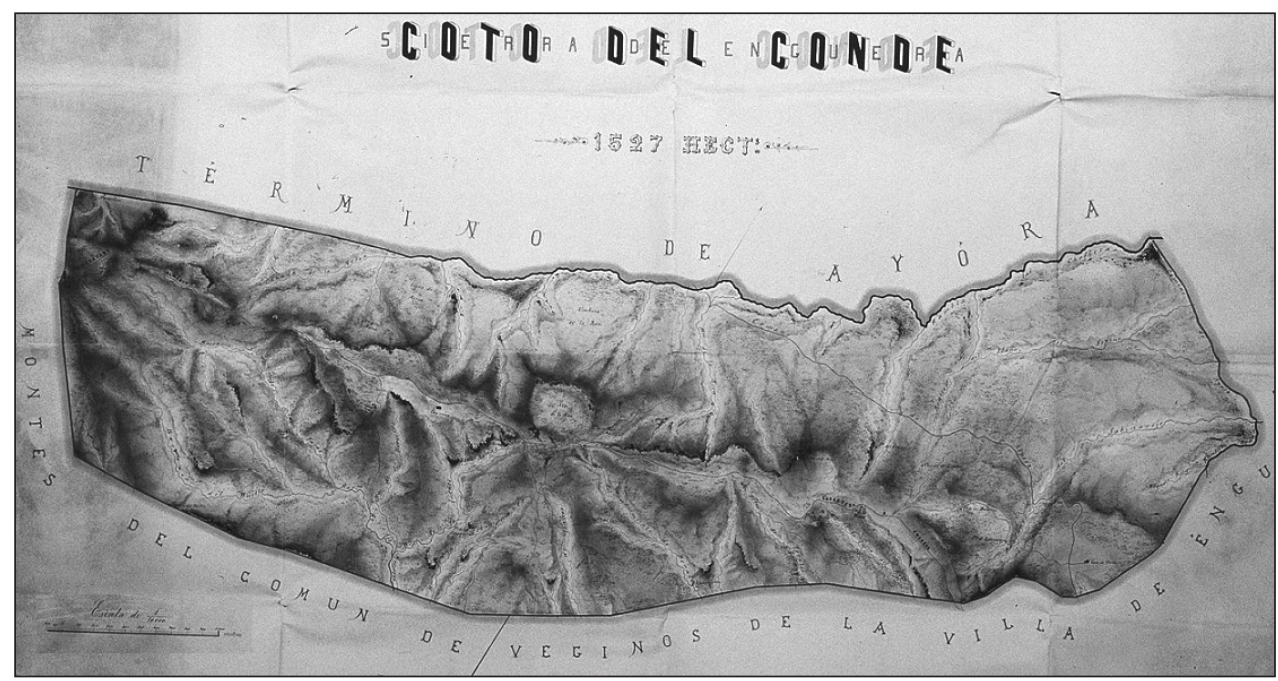

Figura 9. Mapa histórico del Coto del Conde.

supuesto, la casa señorial hubiera sufrido las consecuencias de la intervención del Distrito Forestal, pero hubiera salido ganando, ya que, aunque se hubiera tenido que ajustar a las directrices del ingeniero de montes encargado de aplicar la normativa forestal, hubieran redundado en su favor las restricciones que hubieran tenido que sufrir las servidumbres en el modo de ejecutarlas el pueblo. Sin embargo, el territorio de la Sierra que poseían los vecinos escaparía al control de la administración forestal, lo que requería un deslinde que se antojaba demasiado largo y, por tanto, nada útil. A pesar de todo, convenía al conde la intervención del distrito, para «salvar» a éste, a un mismo tiempo de la intervención y de las servidumbres. En efecto, se utilizaron estos argumentos para encontrar una solución negociada entre ambas partes, pero con la vista puesta el conde en conseguir una propiedad privada. La solución acordada permitió convertir en un bien del común de vecinos el antiguo espacio señorial en 1870, que quedó a salvo de la desamortización por medio de una cláusula precautoria incluida en la escritura. El conde obtuvo en propiedad privada 1.527 Hectáreas, quedando las restantes, que se sumarían a la Redonda, en manos del común de vecinos en dominio útil, sin restricción ni limitación alguna. De este modo, se legalizaban las particularizaciones, antes ilegítimas, operadas por la comunidad rural, y se podían realizar otras en otro escenario distinto.

15. Los montes de Enguera formarían parte del proceso de privatización y de consolidación de un patrimonio forestal público, según ciertos objetivos políticos de los gobernantes del Estado -como el de asegurar en el poder a determinados grupos sociales- en cada momento y por la presión, de distinta naturaleza, que ejercían la evolución de los mercados y la actitud de quienes se veían perjudicados o beneficiados con las medidas que se ponían en práctica. El Ayuntamiento estaba encargado de legitimar las roturaciones arbitrarias. Pero, además, tenía importantes atribuciones respecto de la gestión de sus montes. Hasta 1873-74 tuvo la plena capacidad de gestión de éstos. Después de esa fecha, tenía la primera palabra en cuanto a la defensa de los usos vecinales y al tipo y cantidad de esquilmos que podían extraerse 
de sus montes, mediante la propuesta de aprovechamiento que remitía al Ingeniero Jefe del Distrito para incluirlas en los planes provisionales. Esto es, contaba con un amplio margen de maniobra para condicionar en la práctica la aplicación del plan. Otra cosa era a favor de quien utilizó las competencias en relación a la titularidad y gestión de los montes del pueblo.

La privatización del suelo público no será un proceso igualitario protagonizado por los desposeídos, si atendemos a las actas de los deslindes de principios del siglo XX. El municipio de Enguera comparte un rasgo estructural semejante al que presentan algunas zonas de Andalucía (Jiménez Blanco, 1996), donde las roturaciones fueron especialmente abundantes allí donde por tradición se permitía sembrar libremente en tierras del común, o se procedía a repartos periódicos de parcelas para su cultivo, manteniendo en común el pasto y el aprovechamiento del vuelo.

Así pues, se había fraguado un modelo de ordenación del territorio distinto al pretendido por la casa señorial. En 1869, no se podía implementar un ordenamiento forestal privado, en atención a la amplitud que había alcanzado la acción antrópica y a la entidad de los que estaban construyendo el paisaje.

16. Hasta los primeros años del siglo XX, en Enguera la presumible eficiencia energética neta de esta agricultura orgánica tradicional estaría fundamentada en la integración de la ganadería en el agroecosistema, que transformaba la energía solar captada por parte de los cultivos en la energía necesaria para realizar las labores agrícolas, a la vez que movilizaba los nutrientes que luego eran puestos a disposición de las plantas en las parcelas de mayor potencial agrícola. En otros agroecosistemas de mediados del siglo XIX estudiados (Guzmán Casado y González de Molina, 2006), la dedicación de una parte de las tierras a producir piensos con los que alimentar al ganado de labor y fijar nitrógeno mediante leguminosas se traducía en una rigidez territorial que deprimía con claridad las posibilidades de crecimiento agrario y generaba una huella ecológica sobre los pueblos de sus bordes, donde predominaban los aprovechamientos de secano y eran abundantes las tierras incultas, que le servían de complemento. En el caso enguerino, en cambio, la extensión inculta y los secanos absorbían la necesidades alimenticias del ganado en el interior del propio agroecosistema, lo que ofrecía ciertas posibilidades al crecimiento agrario.

La extensión del cultivo más allá de los límites de aptitud agronómicos en el último tramo del siglo XIX y primeros años del XX, se enmarca en un contexto demográfico distinto al vivido a lo largo del final del siglo XVIII y primeros años del XIX. Al final del siglo XIX, en un contexto de creciente polarización de la sociedad rural y comercialización de la producción, palpable en el fuerte empuje de los viñedos y consolidada la disminución del sector manufacturero, el modo en que se intensificaron los usos del territorio y el control de los derechos de propiedad sobre los recursos naturales se decidieron a escala local.

17. La discusión para delimitar los ámbitos público y privado del territorio, que conllevó a un reparto entre el ex señor y el municipio, se desarrolló en paralelo al pleito mantenido entre ambas partes desde 1846 a 1867 . Este proceso local, sin embargo, representa bien la realidad de la sociedad española del momento. El acuerdo finalmente alcanzado se operó entre el conde y la elite progresista del municipio, con el apoyo popular, los cuales pactaron una solución estable. El modelo territorial existente en vísperas de formalizarse la concordia, y aún antes, hacía imposible en la práctica una operación de desposesión vecinal en toda regla que beneficiase únicamente al ex señor y a la elite local. Hubo más implicados. 
De hecho, la superficie cultivada en 1884 presentaba unos niveles parecidos a los de 1838, es decir, 4.000 Hectáreas. La superficie amillarada sumaba 8.466 Hectáreas, debido a la inclusión de propiedades particulares de monte, principalmente entre las declaraciones de los mayores propietarios. De este modo, el uso del territorio debió incrementarse también para paliar las estrecheces ocasionadas por la pobreza, tras la crisis de la industria o por el desplome del precio de los productos agrarios. Pero las roturaciones del monte se correlacionan positivamente con la tendencia de los precios de la vid, por eso se incrementa su superficie en 1884. Este incremento de las transformaciones del monte sigue una lógica coherente respecto a los incentivos del mercado. La evolución del uso particular del territorio durante la segunda mitad del siglo XIX conformó a un tiempo amplios y pequeños patrimonios en el monte común. El pacto de 1870 ofreció también ciertas oportunidades a la mayoritaria población pluriactiva, al tiempo que se reforzaba la vía agraria en la villa y se depreciaba la industrial, por eso apoyaron la transacción.

La aplicación de la escritura de concordia inaugura, por consiguiente, un escenario nuevo en lo que a la ordenación del territorio se refiere, el cual se prolongará hasta su inclusión en el Catálogo de Montes de Utilidad Pública y el deslinde de estos a principios del siglo XX.

18. El análisis de la gestión privada de la finca Coto del Conde revela un perfil forestal, pecuario y cinegético. La propiedad contenía algunos enclavados particulares consolidados, antes de 1870, que la nueva propiedad tuvo que asumir.

La gestión territorial pública, mediante la práctica del arrendamiento de los aprovechamientos forestales al mejor postor, evidencia la pérdida del carácter comunal de los montes de Enguera. No obstante, el proceso no estuvo exento de contestación. El Ayuntamiento arrendaba los aprovechamientos forestales a los vecinos ricos, o afines al Alcalde. En consecuencia la única salida a los vecinos exceptuados de este negocio era privatizar una porción de monte. Ahora bien, parece detectarse dos tipos de acción usurpadora, por un lado, la que muestran los humildes residentes en Navalón y Boquilla, consiguiendo fincas de reducida extensión superficial y, por otro lado, vecinos propietarios de heredades de relativa importancia que las amplían a costa del monte municipal. Ambos casos pueden tener como denominador común haber sido excluidos de hecho de los arrendamientos.

La comunidad rural que aprovechaba los recursos forestales era muy compleja. El acceso a los recursos del territorio fue dispar entre los componentes de la comunidad rural. Conforme avanzaba el siglo, la industria acabó por sucumbir, creció la emigración y descendió el número total de habitantes desde 1857 hasta 1900 . Al tiempo, los recursos forestales y algunos productos agrarios se revalorizaron, con la ayuda del proteccionismo, lo que provocó una «reconversión» en el modo de uso territorial. Cuando se produjo en Enguera la subordinación del modo de uso campesino a un modo de uso comercial alentado por la legislación forestal estatal, el grupo privilegiado aprovechó esta oportunidad a través de la participación en los arrendamientos al mejor postor y el resto tuvo que optar por aprovechamientos no legitimados por una legislación que se fue adaptando a las necesidades e ideología de los dirigentes.

Los aprovechamientos forestales registrados en la contabilidad municipal revelan un incremento sostenido de los ingresos en el capítulo de Montes a partir de 1905. Ello sugiere que, desde el deslinde de los montes públicos, se inició una nueva etapa en el aprovechamiento. Al parecer, la gestión privada de los recursos forestales de los montes públicos se benefició de manera importante al clarificar los límites del 
espacio público que se podía explotar respecto del privado. Se puede considerar que, en esta etapa, el predominio del modo de uso de la comunidad rural ya estuvo en grado importante subordinado al modo de uso comercial. En camino a esta situación estaría la etapa comprendida entre los años 1894 y 1904, inmediatamente anterior al deslinde, coincidente con el impulso dado a la gestión pública de los montes por el Ayuntamiento desde 1893 -que prueba la divulgación del opúsculo Los Montes de Enguera y el Ayuntamiento-.

Los principales aprovechamientos forestales eran la madera y los pastos. Respecto a la madera, el ingeniero forestal que aprobaba los planes de aprovechamiento forestales municipales otorgaba una capacidad productiva cada año a los montes. El análisis de la contabilidad municipal revela que los ingresos por madera de pino muerto en los incendios eran muy importantes. Puede resultar, también, un modo de flexibilizar los rígidos planes de aprovechamiento supervisados por la Administración forestal. Según parece, los límites ambientales se rebasaron según las necesidades de la sociedad, en función del entendimiento que tuvo del uso de los recursos naturales en cada momento el entramado societario de Enguera.

19. En definitiva, tras la crisis industrial se fue conformando un modelo de crecimiento agrario con dos vías diferentes. Una relacionada con la subsistencia y otra con un perfil netamente comercial. Se fraguó una dualidad agraria entre una economía de autosuficiencia, a base de pequeñas explotaciones, y otra ligada al mercado, que se había dotado de fincas fértiles, con producciones orientadas en función de las señales que iban enviando los mercados. El modelo de especialización productiva del secano estudiado puede calificarse de tardío si se compara con otras regiones españolas. Al parecer, las regiones de la mitad meridional de la península, junto a Cataluña, experimentaron la expansión agraria más robusta durante el siglo XIX.

Era determinante conectarse con los nuevos mercados a través de las nuevas redes de comunicaciones. Conviene mencionar que José Campo, elegido diputado a Cortes por la circunscripción de Enguera, obtuvo la concesión (R. D. de 26 de agosto de 1852) del ferrocarril Xàtiva-Almansa. No obstante, a Enguera no llegó el ferrocarril, aún a pesar de que se trabajó a lo largo de la segunda mitad del siglo XIX en un proyecto de línea férrea que la enlazaría con el nudo de Xàtiva, con dos ramales que tendrían como estación de destino Enguera y Navarrés, respectivamente. Finalmente, la estación de embarque más próxima fue la de L'Alcúdia de Crespins, en la línea Xàtiva-Almansa, puesta en servicio en noviembre de 1857. Por tanto, las producciones enguerinas y de la zona circundante tuvieron que extraerse mediante los vectores tradicionales de transporte, que se fueron adaptando a las nuevas necesidades. Además de la revitalización de los antiguos caminos, a principios del siglo XX se construyó una nueva carretera para enlazar Enguera con L'Alcúdia de Crespins. Del mismo modo que esta vía unía la comarca de Enguera y de La Canal de Navarrés con esta estación ferroviaria de embarque, otra carretera nueva conectaba también Ontinyent y parte de la comarca de la Vall d'Albaida con dicha estación de ferrocarril. Tal fue la atracción del ferrocarril que algunos industriales de Enguera y de la Vall d'Alabaida optaron por instalar sus industrias en L'Alcúdia de Crespins. La estación de l'Alcúdia adquirió gran importancia en el tráfico de mercaderías, así, en el período 1920-23 llegaban una media anual de 9.400 toneladas de cereales, la mitad de todos los productos embarcados. La otra mitad estaba repartida entre productos manufacturados $(10,5 \%)$, abonos $(9,2 \%)$, materiales de construcción $(8,5 \%)$, madera $(8 \%)$ y combustible $(6,5 \%)$. 


\section{ALGUNAS REFLEXIONES FINALES}

Cuando el espacio geográfico va determinándose a partir de los procesos sociales estamos ante paisajes culturales en construcción. La Sierra de Enguera, entre 1580 y 1930, es un espacio geográfico organizado por una cambiante sociedad. Es el espacio en el que se desenvuelve un grupo humano en su interrelación con el medio, por consiguiente es una construcción social, un paisaje humanizado.

El lugar es en geografía la primera unidad de análisis. Desde el análisis del lugar y la localización comienza a tejerse la organización del espacio. Pero, el espacio geográfico está sometido a continuos cambios, cuya variación temporal puede ser de larga o corta duración. Estos cambios hacen que el espacio adopte una apariencia característica y definitoria que denominamos paisaje. Desde un punto de vista histórico, el espacio geográfico es acumulativo, en tanto posee las huellas de las diferentes sociedades que lo organizaron en el proceso histórico. Por tanto, un espacio puede adoptar diferentes paisajes según el momento temporal que consideremos. En consecuencia, los cambios del espacio que configuran diversos paisajes a lo largo del tiempo se derivan de la variación de las interacciones de los elementos que actúan en el paisaje. De este modo la geografía, como ciencia espacial, describe y explica el espacio actual a través de su apariencia o fisonomía, es decir, a través del paisaje. Por ello el estudio de un espacio debe abarcar desde su pasado hasta su presente: sólo así podremos comprender el paisaje actual.

En consecuencia, analizar las dinámicas de la realidad socioeconómica de Enguera puede resultar útil para el conocimiento de la formación local, pero también general, del paisaje valenciano. El impacto de los usos del suelo, la distribución de los cultivos y los recursos forestales y pecuarios en el paisaje dará, como resultado, la determinación del espacio geográfico a través de los procesos sociales desarrollados, entre 1580 y 1930, en la Sierra de Enguera (Pérez Borredà, 2010).

\section{BIBLIOGRAFÍA}

AYUNTAMIENTO DE ENGUERA (1893): Los montes de Enguera y el Ayuntamiento. Fundamentos que este tiene y el Gobierno para administrar los productos forestales pertenecientes al común de vecinos, Imprenta de Fabra, Enguera.

ASINS VELIS, S. (2009): El paisaje agrario aterrazado. Diálogo entre el hombre y el medio en Petrer (Alicante), Universitat de València.

CAPEL SÁEZ, H. (1994) «La invención del territorio. Ingenieros y arquitectos de la Ilustración en España y América», en Actas de las Jornadas sobre la ingeniería militar y la Cultura Artística Española, Cádiz, 13-15 noviembre de 1989. UNED/Fundación Rafael Alberti. Reproducido en Suplementos. Materiales de Trabajo Intelectual, $\mathrm{n}^{\circ}$ 43, pp. 98-115.

- (2005): «Construcción del Estado y creación de cuerpos profesionales científico-técnicos: los ingenieros de la monarquía española en el siglo XVIII», en CÁMARA MUÑOZ, A. y F. COBOS GUERRA (Eds.). Fortificación y Frontera Marítima. Actas del Seminario Internacional celebrado en Ibiza durante los días 24 al 26 de octubre de 2003, Ajuntament d'Eivissa.

FONTANA , J. (2000): La història dels homes. Ed. Crítica, Barcelona.

GARRABOU SEGURA, R. (1985): Un fals dilema: Modernitat o endarreriment de l'agricultura valenciana (1850-1900), Institució Alfons el Magnànim.

GRUPO DE ESTUDIOS DE HISTORIA RURAL (GEHR) (1994): «Más allá de la propiedad perfecta. El proceso de privatización de los montes públicos españoles (1859-1926)», Noticiario de Historia Agraria, no 8, pp. 99-152. 
- (1999): «Diversidad dentro de un orden. Privatización, producción forestal y represión en los montes públicos españoles, 1859-1926», Historia Agraria, nº 18, pp. 129-178.

- (2002): «Política forestal y producción de los montes públicos españoles. Una visión de conjunto, 1861-1933», Revista de Historia Económica, Año XX, nº 3, pp. 509-541.

GIMÉNEZ FONT, P. (2008): Las transformaciones del paisaje valenciano en el siglo XVIII: una perspectiva geográfica. Institució Alfons el Magnànim.

GUZMÁN CASADO, G. y GONZÁLEZ DE MOLINA, M. (2006): «Sobre las posibilidades de crecimiento agrario en los siglos XVIII, XIX y XX. Un estudio de caso desde la perspectiva energética», Historia Agraria, no 40, pp. 437-470.

HERNÁNDEZ MARCO, J. L. (1976): «El Colbertismo de Felipe V y Valencia: la política textil no sedera», Estudis, n ${ }^{\circ}$ 5, pp. 47-58.

- (1980): Estructura económica e industrialización. Enguera y Bocairent durante los siglos XVIII y XIX, Tesis de Doctorado, Universidad de Valencia.

- (1987): «La pañería como alternativa económica de las serranías del interior valenciano (siglos XVIII y XIX)», Saitabi, no 37, pp. 209-234.

HERNÁNDEZ MARCO, J.L. y ROMERO GONZÁLEZ, J. (1980): Feudalidad, burguesía y campesinado en la Huerta de Valencia, Ayuntamiento de Valencia.

JIMÉNEZ BLANCO, J. I. (1996): Privatización y apropiación de tierras municipales en la Baja Andalucía: Jerez de la Frontera, 1750-1995, Ayuntamiento de Jerez.

MATEU BELLES, J.F. (2001): «El geògraf Vicenç M. Rosselló Verger i la interpretació històrica del territori» en Afers, $\mathrm{n}^{\circ}$ 40, pp. 541-548.

MENDIZÁBAL RIERA, E. (1993): «El temps en geografia humana» en Professor Lluís Casassas. Geografia i territorio, Universitat de Barcelona, pp. 53-61.

MILLÁN GARCÍA-VARELA, J. (2008): «Una petjada identitària. Els canvis en l'espai durant el triomf de l'agricultura a l'extrem sud valencià», Afers nº 61, pp. 742-758.

ORTEGA VALCÁRCEL, J. (2000): Los horizontes de la geografía. Teoría de la geografía. Barcelona, Ariel (Geografía).

- (2004): «La Geografía para el siglo XXI», en Romero, J. (coord.), Geografía Humana. Procesos, riesgos e incertidumbres en un mundo globalizado, Barcelona, Ariel, pp. 25-53.

PÉREZ BORREDÀ, J. R. (2009), Transformar la naturaleza. El modelo de crecimiento agrario del siglo XIX y sus límites ambientales en el secano central valenciano (15801930), Tesis Doctoral, Universitat de València.

- (2009) «Formación de enclavados particulares en el proceso de cambio del monte comunal. La Sierra de Enguera, 1838-1930», en S. de Dios, J. Infante, R. Robledo, E. Torijano (Coords.), Historia de la Propiedad. Servidumbres y Limitaciones de Dominio. VI Encuentro Interdisciplinar, Salamanca, 17-19 de septiembre de 2008, pp. 543-573.

- (2011): Construyendo paisajes mediterráneos. Apropiación de tierras y transformación del paisaje en la Sierra de Enguera (1580-1930), Universitat de València.

PESET REIG, M. y HERNANDO SERRA, P. (2001): «Comunales y propios en Valencia», en S. de Dios, J. Infante, R. Robledo, E. Torijano (Coords.), Historia de la propiedad en España. Bienes comunales, pasado y presente, II Encuentro Interdisciplinar, Salamanca, 31 de mayo-3 de junio, Servicio de Estudios del Colegio de Registradores, Madrid, pp. 179-210.

PRO RUIZ, J. (1992): Estado, geometría y propiedad. Los orígenes del catastro en España (1715-1941), Ministerio de Economía y Hacienda, Madrid.

- (1996): «Ocultación de la riqueza rústica en España (1870-1936): acerca de la fiabilidad de las estadísticas sobre la propiedad y uso de la tierra», Revista de Historia Económica, n 1 , pp. 89-114. 
- (1997): «Sistemas fiscales y estadística agraria en la España del siglo XIX», Actas del VI Congreso de la Asociación de Historia Económica (5ª Sesión), Girona.

ROMERO GONZÁLEZ, J. (2009): Prólogo a Asins Velis, S., El paisaje agrario aterrazado. Diálogo entre el hombre y el medio en Petrer (Alicante), Valencia, Universitat de València, p.11.

RUIZ TORRES, P. (1981): Señores y propietarios. Cambio social en el sur del País Valenciano, 1650- 1850, Institució Alfons el Magnànim, Valencia.

SALA LÓPEZ, P. (1998): Sobre la compatibilitat entre bosc protector i bosc productor (la Catalunya forestal humida entre la societat agraria i la societat industrial, 1850-1930), Tesis Doctoral, Universitat Autònoma de Barcelona.

TELLO ARAGAY, E. (2004): «La petjada ecològica del metabolisme social: una proposta metodològica per analitzar el paisatge com a humanització del territori», Manuscrits, $\mathrm{n}^{\mathrm{o}} 22$, pp. 59-82. 
